\title{
Pengaruh Jarak Tanam Jajar Legowo dan Jumlah Bibit terhadap Pertumbuhan dan Hasil Padi Sawah
}

\author{
The Effect of "Jajar Legowo" Planting Distance and Number of Seeds on Growth and Yield of Rice Fields \\ Khairil $^{1 *}$, Radian$^{1}$, dan Wasi'an ${ }^{1}$ \\ ${ }^{1}$ Program Studi Magister Agroteknologi Fakultas Pertanian, Universitas Tanjungpura, Pontianak \\ *Email korespondensi: arielktp003@gmail.com
}

Diterima: 06 Juli 2020 / Disetujui: 15 September 2020

\begin{abstract}
Rice is the main food of Indonesian population. The aim of this research to study the effectt of jajar legowo planting distance and the number of seeds per planting hole to the growth and yield of rice fields. This research used a two-factor randomized design. Spacing of legowo row 2: 1 (j1) $10 \mathrm{~cm} \times 20 \mathrm{~cm}$, (j2) $20 \mathrm{~cm} \times 20 \mathrm{~cm}$, (j3) $20 \mathrm{~cm} \times 25 \mathrm{~cm}$, (j4) $25 \mathrm{~cm} \times 25 \mathrm{~cm}$. The number of seeds per planting (b1) 1 stem, (b2) 5 stems, (b3) 10 stems, (b4) 15 stems, (b5) 20, (b6) 25 stems. The results showed a significant spacing of 45 hour-old plant height, significantly affected the number of tillers aged 25,35,45 hours, productive tillers and grain weight per clump, number of seeds per planting hole was very beneficial to 15-hour-old plant height, tillers 15,25,35,45 hours old and productive tillers.
\end{abstract}

Keywords: jajar legowo, paddy, planting distance, seeds.

\section{ABSTRAK}

Padi merupakan bahan makanan pokok penduduk Indonesia. Tujuan penelitian adalah untuk mengetahui pengaruh jarak tanam jajar legowo dan jumlah bibit per lubang tanam terhadap pertumbuhan dan hasil padi sawah. Penelitian menggunakan Rancangan Acak Kelompok dua faktor. Jarak tanam jajar legowo 2:1 (j1) $10 \mathrm{~cm} \times 20 \mathrm{~cm}$, (j2) $20 \mathrm{~cm} \times 20 \mathrm{~cm}$, (j3) $20 \mathrm{~cm} \times 25$ $\mathrm{cm}$, (j4) $25 \mathrm{~cm} \times 25 \mathrm{~cm}$. Jumlah bibit perlubang tanam (b1) lbatang, (b2) 5 batang, (b3) 10 batang, (b4) 15 batang, (b5) 20, (b6) 25 batang. Hasil penelitian menunjukkan jarak tanam berpengaruh nyata terhadap tinggi tanaman umur 45 hst, berpengaruh sangat nyata terhadap jumlah anakan umur 25,35,45 hst, anakan produktif dan berat gabah per rumpun, jumlah bibit per lubang tanam berpengaruh sangat nyata terhadap tinggi tanaman umur 15 hst, anakan umur 15, 25, 35, 45 hst dan anakan produktif.

Kata kunci: jarak tanam, jajar legowo, jumlah bibit, padi

\section{PENDAHULUAN}

Padi merupakan bahan pangan makanan utama penduduk Indonesia. Konsumsi beras rata-rata 139 $\mathrm{kg} / \mathrm{kapita} /$ tahun dengan total kebutuhan beras 32.66 juta ton/tahun. Pertambahan penduduk mendorong peningkatan kebutuhan akan beras, oleh karena itu perlu peningkatan produksi beras untuk memenuhi kebutuhan tersebut. Upaya memenuhi padi masyarakat, salah satu caranya adalah peningkatan produktivitas padi nasional melalui pengaturan jarak tanam sistem jajar legowo dan jumlah bibit per lubang tanam. Istilah legowo diambil dari bahasa jawa dari kata lego berarti luas dan dowo berarti memanjang.

Jajar legowo adalah suatu rekayasa teknologi untuk mendapatkan peningkatan populasi perhektar. Penerapan jajar legowo selain meningkatkan populasi, juga diharapkan memberikan produksi yang lebih tinggi dan kualitas gabah yang lebih baik, mengingat pada sistem jajar legowo terdapat ruang terbuka seluas $25-50 \%$, sehingga tanaman dapat menerima sinar matahari secara optimal yang berguna dalam proses fotosintesis (Balitbangtan, 2013).
Penerapan sistem tanam jajar legowo yang sesuai dengan kondisi lingkungan setempat hampir dapat dipastikan akan meningkatkan produktivitas tanaman padi dan keuntungan bagi petani, sedangkan perluasannya secara nasional dapat meningkatkan produksi padi (Lin et al.., 2009).

Jarak tanam yang optimum akan memberikan pertumbuhan bagian atas tanaman dan pertumbuhan bagian akar yang baik sehingga dapat memanfaatkan cahaya dan unsur hara. Sebaliknya, jarak tanam yang terlalu rapat akan mengakibatkan terjadinya kompetisi antar tanaman dalam memperebutkan cahaya,air dan unsur hara. Pertumbuhan tanaman terhambat dan hasil tanaman rendah (Sohel et al.,. 2009).

Jumlah bibit perlubang tanam sangat terkait dengan persaingan tanaman dalam satu rumpun maupun dengan rumpun lainnya terhadap cahaya, ruang dan pemanfaatan unsur hara, sehingga dapat mempengaruhi pertumbuhan dan produksi tanaman padi. (Utami et al.., 2016) bahwa dengan penanaman 1-4 batang perlubang tanam rata-rata tinggi tanaman jumlah daun, jumlah anakan total, jumlah anakan produktif, berat 100 biji gabah, berat gabah kering giling per 
Balitbangtan (2015), menyatakan dengan penanaman 20 sampai 30 bibit perlubang tanam dapat memberikan efek peningkatan hasil padi persatuan luas lahan.

Melihat berbagai kondisi diatas maka perlu pengkajian tentang jarak tanam dengan sistem jajar legowo dan jumlah bibit perlubang tanam guna meningkatkan kualitas produktivitas tanaman padi yang lebih baik.

\section{BAHAN DAN METODE}

\section{Tempat dan waktu penelitian}

Penelitian dilaksanakan di Kabupaten Kayong Utara Kalimantan Barat pada lahan sawah percontohan Balai Penyuluhan Pertanian Perkebunan dan Kelautan (BP3K). Waktu peneletian lebih kurang 4 bulan mulai bulan Desember 2017 sampai bulan April 2018.

\section{Rancangan penelitian}

Penelitian menggunakan Rancangan Acak Kelompok (RAK) 2 faktor di ulang sebanyak 3 kali sehingga didapat 72 satuan perlakuan : Faktor pertama jarak janam jajar legowo 2:1: (j1) jarak tanam $10 \mathrm{~cm}$ x $20 \mathrm{~cm},(\mathrm{j} 2)$ jarak tanam $20 \mathrm{~cm}$ x $20 \mathrm{~cm}$, (j3) jarak tanam $20 \mathrm{~cm}$ x $25 \mathrm{~cm}$, (j4) jarak tanam 25 $\mathrm{cm}$ x $25 \mathrm{~cm}$. Faktor kedua jumlah bibit perlubang tanam (b1) 1 batang perlubang tanam, (b2) 5 batang perlubang tanam, (b3) 10 batang perlubang tanam, (b4) 15 batang perlubang tanam, (b5) 20 batang perlubang tanam, (b6) 25 batang perlubang tanam.

\section{Variabel pengamatan}

Variabel pengamatan, tinggi tanaman $(\mathrm{cm})$, jumlah anakan (batang), jumlah anakan produktif (batang), berat gabah per rumpun (g), berat gabah 1000 butir (g), berat gabah per petak $(\mathrm{kg})$, berat gabah $\left(\mathrm{t} \mathrm{Ha}^{-1}\right)$.

\section{Analisis statistik}

Analisa data menggunakan Uji $\mathrm{F}$ tabel ANOVA, apabila perlakuan berpengaruh nyata atau sangat nyata maka dilanjutkan dengan uji Beda Nyata Jujur (BNJ) pada taraf 5\%

\section{HASIL DAN PEMBAHASAN}

\section{Tinggi Tanaman}

Hasil $\mathrm{F}$ tabel pada analisis keragaman menunjukkan bahwa jarak tanam berpengaruh nyata terhadap tinggi tanaman dan berpengaruh sangat nyata terhadap perlakuan jumlah bibit ditampilkan pada Tabel 1 .

Berdasarkan hasil Tabel 1 pertambahan ukuran tinggi tanaman pada perlakuan jarak tanam pengamatan 45 HST menunjukkan hasil yang berbeda nyata. Rata-rata tinggi tanaman pada jarak tanam $(10 \mathrm{~cm}$ x 20 dan $20 \mathrm{~cm}$ x $20 \mathrm{~cm})$ menghasilkan tinggi tanaman yang sama, sedangkan jarak tanam ( $20 \mathrm{~cm}$ x $25 \mathrm{~cm}$ dan $25 \mathrm{~cm}$ x $25 \mathrm{~cm}$ ) juga menghasilkan tinggi tanaman yang sama. Pada perlakuan jumlah bibit berbeda sangat nyata pada pengamatan 15 HST. Rata-rata tinggi tanaman $(25,20,15$ dan 1$)$ batang menghasilkan tinggi tanamanyang sama, terendah terdapat pada perlakuan jumlah bibit 5 dan 10 batang.

Tingginya jarak tanam yang sempit dan jumlah bibit yang banyak tidak lepas dari jumlah tajuk tanaman lebih cepat saling menanungi antar tanaman yang satu dengan yang lainnya. Sehingga tanaman berkompetisi dalam mendapatkan ruang tumbuh terutama cahaya matahari. Penerimaan cahaya matahari yang sedikit menyebabkan tanaman cenderung mengalami pemanjangan batang ke arah atas, sehingga pada jarak tanam yang rapat dan jumlah bibit yang banyak tanaman cenderung lebih tinggi dibandingkan jarak tanam yang lebar dan jumlah bibit sedikit. Hal ini sesuai dengan pernyataan Habibie at al. (2011) cahaya matahari berpengaruh besar terhadap pertumbuhan batang dan daun. Kekurangan cahaya menyebabkan tanaman mengalami etiolasi atau pemanjangan

Tabel 1. Pengaruh perlakuan terhadap tinggi tanaman umur 15, 25, 35, dan 45 HST.

\begin{tabular}{|c|c|c|c|c|}
\hline \multirow{2}{*}{$\begin{array}{l}\text { Perlakuan } \\
\text { Jarak Tanam }\end{array}$} & \multicolumn{4}{|c|}{ Tinggi tanaman $(\mathrm{cm})$} \\
\hline & 15 & 25 & 35 & 45 \\
\hline $10 \mathrm{~cm} \times 20 \mathrm{~cm}$ & $41,01 \mathrm{a}$ & 48,19 a & $63,50 \mathrm{a}$ & $71,94 \mathrm{a}$ \\
\hline $20 \mathrm{~cm} \times 20 \mathrm{~cm}$ & $40,52 \mathrm{a}$ & $46,44 \mathrm{a}$ & 63,22 a & $69,86 \mathrm{ab}$ \\
\hline $20 \mathrm{~cm} \times 25 \mathrm{~cm}$ & $41,26 \mathrm{a}$ & $47,23 \mathrm{a}$ & 63,65 a & $68,85 \mathrm{~b}$ \\
\hline $25 \mathrm{~cm} \mathrm{x} 25 \mathrm{~cm}$ & 39,53 a & 48,16 a & $63,01 \mathrm{a}$ & $68,60 \mathrm{~b}$ \\
\hline BNJ $5 \%$ & $\operatorname{tn}$ & tn & tn & 2,95 \\
\hline \multicolumn{5}{|l|}{ Jumlah Bibit } \\
\hline 1 Batang & $41,01 \mathrm{ab}$ & $46,91 \mathrm{a}$ & $62,54 \mathrm{a}$ & $68,26 \mathrm{a}$ \\
\hline 5 Batang & $37,65 \mathrm{c}$ & $46,48 \mathrm{a}$ & $62,31 \mathrm{a}$ & $67,97 \mathrm{a}$ \\
\hline 10 Batang & $39,42 \mathrm{bc}$ & $47,47 \mathrm{a}$ & $63,77 \mathrm{a}$ & 70,5 a \\
\hline 15 Batang & $41,36 \mathrm{ab}$ & $48,89 \mathrm{a}$ & $63,76 \mathrm{a}$ & $69,79 \mathrm{a}$ \\
\hline 20 Batang & $41,49 \mathrm{ab}$ & $48,13 \mathrm{a}$ & $6518 \mathrm{a}$ & $71,86 \mathrm{a}$ \\
\hline 25 Batang & $42,53 \mathrm{a}$ & $47,18 \mathrm{a}$ & $62,50 \mathrm{a}$ & $70,48 \mathrm{a}$ \\
\hline BNJ 5\% & 2,84 & $\operatorname{tn}$ & $\operatorname{tn}$ & tn \\
\hline
\end{tabular}

Keterangan: Bilangan yang diikuti oleh huruf yang sama pada kolom yang sama tidak berbeda nyata pada uji BNJ 5\%. 
Tabel 2. Pengaruh perlakuan terhadap jumlah anakan umur 15, 25, 35, dan 45 HST dan anakan produktif.

\begin{tabular}{|c|c|c|c|c|c|}
\hline \multirow{2}{*}{$\begin{array}{l}\text { Perlakuan } \\
\text { Jarak Tanam }\end{array}$} & \multicolumn{5}{|c|}{ Jumlah anakan dan anakan produktif (batang) } \\
\hline & 15 & 25 & 35 & 45 & AP \\
\hline $10 \mathrm{~cm} \times 20 \mathrm{~cm}$ & $16,79 \mathrm{a}$ & $20,85 \mathrm{c}$ & $18,47 \mathrm{~d}$ & $19,11 \mathrm{c}$ & $16,11 \mathrm{c}$ \\
\hline $20 \mathrm{~cm} \times 20 \mathrm{~cm}$ & $17,79 \mathrm{a}$ & $28,99 \mathrm{~b}$ & $24,19 \mathrm{c}$ & $22,13 \mathrm{bc}$ & $19,03 \mathrm{bc}$ \\
\hline $20 \mathrm{~cm} \times 25 \mathrm{~cm}$ & $17,96 \mathrm{a}$ & $31,19 a b$ & $26,87 \mathrm{~b}$ & $23,16 \mathrm{~b}$ & $19,97 \mathrm{~b}$ \\
\hline $25 \mathrm{~cm} \times 25 \mathrm{~cm}$ & $17,79 \mathrm{a}$ & $33,57 \mathrm{a}$ & $29,27 \mathrm{a}$ & $27,61 \mathrm{a}$ & $24,53 \mathrm{a}$ \\
\hline BNJ 5\% & tn & 2,48 & 1,98 & 3,77 & 3,75 \\
\hline \multicolumn{6}{|l|}{ Jumlah Bibit } \\
\hline 1 Batang & $8,17 \mathrm{f}$ & $18,86 \mathrm{c}$ & $17,76 \mathrm{~d}$ & $20,06 \mathrm{~b}$ & $16,93 \mathrm{~b}$ \\
\hline 5 Batang & $12,29 \mathrm{e}$ & $27,04 \mathrm{~b}$ & $23,76 \mathrm{c}$ & $20,83 \mathrm{~b}$ & $17,72 \mathrm{~b}$ \\
\hline 10 Batang & $15,55 \mathrm{~d}$ & $28,60 \mathrm{~b}$ & $24,72 \mathrm{bc}$ & $20,29 \mathrm{~b}$ & $17,24 \mathrm{~b}$ \\
\hline 15 Batang & $18,89 \mathrm{c}$ & $29,60 \mathrm{~b}$ & $25,41 \mathrm{bc}$ & $22,83 \mathrm{~b}$ & $19,77 \mathrm{~b}$ \\
\hline 20 Batang & $23,43 b$ & $33,68 \mathrm{a}$ & $27,37 \mathrm{ab}$ & $25,09 \mathrm{ab}$ & $22,05 \mathrm{ab}$ \\
\hline 25 Batang & $27,10 \mathrm{a}$ & $34,10 \mathrm{a}$ & $29,20 \mathrm{a}$ & $28,74 \mathrm{a}$ & $25,60 \mathrm{a}$ \\
\hline BNJ 5\% & 1,71 & 3,39 & 2,70 & 5,14 & 5,12 \\
\hline
\end{tabular}

Keterangan: Bilangan yang diikuti oleh huruf yang sama pada kolom yang sama tidak berbeda nyata pada uji BNJ 5\%.

Tabel 3. Pengaruh perlakuan terhadap komponen panen.

\begin{tabular}{|c|c|c|c|c|}
\hline \multirow{2}{*}{$\begin{array}{l}\text { Perlakuan } \\
\text { Jarak Tanam }\end{array}$} & \multicolumn{4}{|c|}{ Komponen panen } \\
\hline & $\begin{array}{l}1000 \\
(\mathrm{~g})\end{array}$ & $\begin{array}{l}\text { Per rumpun } \\
(\mathrm{g})\end{array}$ & $\begin{array}{c}\text { Per petak } \\
(\mathrm{kg})\end{array}$ & $\begin{array}{l}\text { Produksi } \\
\left(\text { ton } \mathrm{Ha}^{-1}\right)\end{array}$ \\
\hline $10 \mathrm{~cm} \times 20 \mathrm{~cm}$ & $28,72 \mathrm{a}$ & $21,29 \mathrm{~b}$ & $2,65 \mathrm{a}$ & $4,25 \mathrm{a}$ \\
\hline $20 \mathrm{~cm} \mathrm{x} 20 \mathrm{~cm}$ & $28,56 \mathrm{a}$ & $24,07 \mathrm{~b}$ & $2,64 \mathrm{a}$ & $4,23 \mathrm{a}$ \\
\hline $20 \mathrm{~cm} \mathrm{x} 25 \mathrm{~cm}$ & 29,18 a & $30,56 \mathrm{a}$ & $2,59 \mathrm{a}$ & 4,16 a \\
\hline $25 \mathrm{~cm} \times 25 \mathrm{~cm}$ & $29,22 \mathrm{a}$ & $31,94 \mathrm{a}$ & $2,49 \mathrm{a}$ & $3,99 \mathrm{a}$ \\
\hline BNJ 5\% & $\operatorname{tn}$ & 5,56 & $\operatorname{tn}$ & tn \\
\hline \multicolumn{5}{|l|}{ Jumlah Bibit } \\
\hline 1 Batang & $28,17 \mathrm{a}$ & 28,47 a & $2,64 \mathrm{a}$ & $4,23 \mathrm{a}$ \\
\hline 5 Batang & 29,17 a & $27,78 \mathrm{a}$ & $2,68 \mathrm{a}$ & $4,29 \mathrm{a}$ \\
\hline 10 Batang & $29,12 \mathrm{a}$ & $23,61 \mathrm{a}$ & $2,67 \mathrm{a}$ & $4,27 \mathrm{a}$ \\
\hline 15 Batang & $28,92 \mathrm{a}$ & $29,86 \mathrm{a}$ & $2,26 \mathrm{a}$ & $4,17 \mathrm{a}$ \\
\hline 20 Batang & $28,83 \mathrm{a}$ & $27,78 \mathrm{a}$ & $2,58 \mathrm{a}$ & $4,13 \mathrm{a}$ \\
\hline 25 Batang & $28,58 \mathrm{a}$ & $24,31 \mathrm{a}$ & $2,4 \quad a$ & $3,84 \mathrm{a}$ \\
\hline
\end{tabular}

Keterangan : Bilangan yang diikuti oleh huruf yang sama pada kolom yang sama tidak berbeda nyata pada uji BNJ 5\%.

batang yang diikuti daun mencari sumber cahaya matahari, sehingga penampilan tanaman akan lebih tinggi dari pada tanaman yang cukup cahaya.

Anugrah et al. (2008) menambahkan pertumbuhan tinggi dan diameter tanaman dipengaruhi oleh cahaya, pertumbuhan tinggi lebih cepat pada tempat ternaungi dari pada tempat terbuka.

\section{Jumlah Anakan dan Anakan Produktif}

Hasil uji $\mathrm{F}$ tabel analisis keragaman menunjukkan bahwa perlakuan jarak tanam dan perlakuan jumlah bibit sama-sama berpengaruh sangat nyata terhadap jumlah anakan dan anakan produktif ditampilkan pada Tabel 2.

Berdasarkan hasil Tabel 2 menunjukkan bahwa perlakuan jarak tanam berbeda nyata pada pengamatan $(25$, 35, 45 HST), dan anakan produktif . Rata-rata jumlah anakan dan anakan produktif pada perlakuan jarak tanam $(25 \mathrm{~cm} \mathrm{x}$ $25 \mathrm{~cm}$ ) lebih tinggi dibandingkan dengan perlakuan jarak tanam dan anakan produktif yang lainnya. Jumlah anakan terendah terdapat pada jarak tanam $(10 \mathrm{~cm} \times 20 \mathrm{~cm})$. Tingginya jumlah anakan yang dan anakan produktif yang dihasilkan jarak tanam yang lebar karena tanaman lebih optimal dalam pemanfaatan intensitas cahaya matahari, unsur hara dan air sehingga mempengaruhi pertumbuhan dan produksi tanaman. Hal ini sesuai dengan tulisan Putra dan Sebayang, (2018) jarak tanam yang lebar memberikan pengaruh terbaik terhadap jumlah anakan dan anakan produktif dibandingkan dengan jarak tanam yang sempit karena tanaman lebih leluasa mendapatkan nutrisi dan cahaya matahari sehingga lebih optimal dalam melaksanakan metabolisme.

Perlakuan jumlah bibit berbeda nyata pada semua pengamatan. Jumlah anakan dan anakan produktif pada 
perlakuan jumlah bibit 25 batang lebih tinggi dibandingkan dengan perlakuan jumlah bibit yang lainnya. Jumlah bibit terendah terdapat pada 1 batang. Tingginya jumlah anakan dan anakan produktif yang dihasilkan pada perlakuan jumlah bibit yang banyak ada kecendrungan pengaruh banyaknya jumlah bibit yang ditanam.

Akan tetapi apabila dililihat dari jumlah rata-rata anakan dan anakan produktif yang dihasilkan penanaman bibit sedikit lebih tinggi dibandingkan dengan jumlah anakan dan anakan produktif yang dihasilkan penanaman bibit yang banyak. Muyassir, (2012) menyatakan semakin banyak jumlah bibit, semakin sedikit jumlah anakan produktif. Hal ini disebakan adanya persaingan sejak awal antar lembaran daun secara langsung akan menurunkan kebugaran (vigor) anakan.

\section{Komponen Hasil}

Hasil uji $\mathrm{F}$ tabel analisis keragaman menunjukkan bahwa jarak tanam berpengaruh sangat nyata terhadap pengamatan komponen hasil panen berat gabah perrumpun dan tidak berpengaruh nyata pada pengamatan komponen panen berat gabah 100 butir, per petak $\left(\mathrm{t} \mathrm{Ha}^{-1)}\right.$ dan ditampilkan pada Tabel 3 .

Berdasarkan hasil Tabel 3 komponen hasil panen menunjukkan bahwa jarak tanam berbeda nyata terhadap pengamatan berat gabah per rumpun. Rata-rata berat gabah per rumpun jarak tanam $(20 \mathrm{~cm} \times 25 \mathrm{~cm}$ dan $25 \mathrm{~cm} \times 25 \mathrm{~cm})$ menghasilkan berat gabah yang sama, sedangkan berat gabah jarak tanam $(10 \mathrm{~cm} \times 20 \mathrm{~cm}$ dan $20 \mathrm{~cm} \times 25 \mathrm{~cm})$ juga menghasilkan berat gabah per rumpun yang sama.

Tingginya berat gabah per rumpun terhadap jarak tanam yang lebar karena tanaman lebih efisien dalam penggunaan cahaya dalam proses fotosintesis yang akhirnya akan mempenguruhi pertumbuhan dan hasil tanaman. Dari proses fotosintesis tersebut tanaman menghasilkan fotosintat yang dapat menghasilkan biomassa tanaman. Hal ini sesui dengan tulisan Habibie et al.. (2011) bahwa biomassa tanaman yang tersusun mempengaruhi pembentukan anakan sehingga anakan yang dihasilkan menjadi lebih banyak. Jumlah anakan yang banyak dapat mempengaruhi hasil berat gabah per rumpun karena jumlah anakan yanag banyak maka anakan produktif juga ikut banyak.

Yetti dan Ardian, (2010) menambahkan anakan produktif yang dihasilkan gambaran dari hasil jumlah anakan maksimum yang telah dihasilkan sebelumnya. Anakan produktif tersebut akan membentuk menjadi malai. Hasil berat gabah per rumpun berbanding lurus dengan jumlah anakan dan anakan produktif pada pengamatan. Jarak tanam yang lebar memberikan hasil yang tinggi dibandingkan dengan jarak tanam yang sempit.

Perlakuan jumlah bibit perlubang tanam tidak berbeda nyata pada semua parameter pengamatan komponen hasil panen. Hal ini diduga penanaman bibit yang sedikit tanaman lebih leluasa mendapatkan unsur hara untuk prose pertumbuhan dan perkembangan vegetatif sampai generatif sehingga hasilnya maksimal. Sedangkan perlakuan jumlah bibit yang banyak tanaman tidak mendapatkan asupan unsur hara yang maksimal dikarenakan terjadi kompetesi antar individu tanaman dan mempengaruhi hasil produksi, sehingga jumlah bibit sedikit dan jumlah bibit yang banyak sama-sama menghasilkan komponen panen yang sama.

Walaupun pengamatan komponen hasil panen tidak berbeda nyata,apabila dilihat hasil rata-rata pada parameter pengamatan berat gabah 1000 butir dan berat gabah per rumpun pada perlakuan jarak tanam yang lebar memberikan hasil yang tinggi dibandingkan dengan jarak tanam yang lain, akan tetapi hasil komponen panen jarak tanam yang lebar tidak dikikuti ole hasil berat gabah $\left(\mathrm{t} \mathrm{h}^{-1}\right)$, hal ini karena hasil persatuan luas rendah, karena rendahnya jumlah tanaman. Hasil $\left(\mathrm{t} \mathrm{h}^{-1}\right)$ pada perlakuan jumlah bibit yang banyak juga ikut rendah dibandingkan dengan yang lainnya, karena tanaman berkompetisi sampai akhir pertumbuhan sehingga produksinyapun ikut rendah.

\section{KESIMPULAN}

Jarak tanam berpengaruh nyata terhadap tinggi tanaman pengamatan 45 hst dan berpengaruh sangat nyata terhadap jumlah anakan pengaatan $25,35,45$ hst, anakan produktif dan berat gabah per rumpun. Jumlah bibit berpengaruh sangat nyata terhadap tinggi tanaman pengamatan $15 \mathrm{hst}$, anakan pengamatan 15,25,35,45 hst dan anakan produktif. Jarak tanam dan jumlah bibit tanam samasama memberikan hasil yang optimum $\left(\mathrm{t} \mathrm{h}^{-1}\right)$ terhadap hasil padi sawah.

\section{DAFTAR PUSTAKA}

Anugrah, I. S, Sumedi, I. P. \& Wardana. (2008) Gagasan dan Implementasi System of Rice Intensification (SRI) Dalam Kegiatan Budidaya Padi Ekologis (BPE). Analisis Kebijakan Pertanian. 6, 1. DOI: http://dx.doi.org/10.21082/akp.v6n1.2008.7599.

Balitbangtan. (2013). Sistem Tanam Legowo. Kementrian Pertanian.

Balitbangtan. (2015). Panduan Teknologi Budidaya Hazton Pada Tanaman Padi. Kementrian Pertanian.

Habibie, A. F, Nugroho, A., \& Suryanto, A. (2011). Kajian pengaturan jarak tanam dan irigasi berselang (intermittent irrigation) pada Metode SRI (system of rice intensification) terhadap produktivitas tanaman padi (Oryza sativa L.) varietas Ciherang. Universitas Brawijaya.

Lin, X. Q., Zhu, D. F., Chen, H. Z., \& Zhang, Y. P. (2009). Effects of plant density and nitrogen application rate on grain yield and nitrogen uptake of super hybrid rice. Rice science, 16(2), 138-142. DOI: https://doi.org./10./1016/S1672-6308(08)60070-0.

Muyassir, M. (2012). Efek jarak tanam, umur dan jumlah bibit terhadap hasil padi sawah (Oryza sativa L.). Jurnal Manajemen Sumberdaya Lahan, 1(2), 207-212. 
Putra, B. S., \& Sebayang, H. T. (2019). Pengaruh umur bibit terhadap pertumbuhan dan hasil tanaman padi (Oryza sativa L.) Pada 2 macam sistem tanam. Jurnal Produksi Tanaman, 6(8).

Sohel, M. A. T, Siddique, M. A. B., Asaduzzaman, M., Alam, M. N., \& Karim, M.M. (2009). Varietal performance of transplant aman rice under different hill densities. Bangladesh J. Agril. Res. 34, 1, 33-39.
Utami, S. N. H, Achmadi, P., \& Subejo. (2016). Penerapan teknologi tepat guna padi sawah spesifik lokasi di Dusun Ponggok, Trimulyo, Jetis, Bantul. Indonesia Journal of Comunity Engagement. 1, 2. DOI: https://doi.org/10.22146/jpkm.10610.

Yetti, H., \& Ardian. (2010). Pengaruh jarak tanam terhadap pertumbuhan produksi padi sawah (Oriza sativa L.) Varietas ir 42 dengan metode SRI (system of rice intensification). Journal Sagu, 9, 1. 